Original Research Paper

\title{
Technology Can Save the Environment
}

Peter Bisong Bisong ${ }^{1}$, Sylvester Apologun ${ }^{2 *}$

${ }^{1}$ University of Calabar, Nigeria.

${ }^{2}$ Delta State College of Education, Nigeria

Article History

Received:

28.05.2020

Revised:

25.06.2020

Accepted:

27.06.2020

*Corresponding Author:

Sylvester Apologun

Email:

pbbisong@yahoo.com
Abstract: The environment is fast degrading. Experts believe that in the nearest future, the environment will collapse, if the current rate of degradation continues. One of the main drivers of this degradation is believed to be technology. This has led to the widespread perception of technology as a curse rather than a blessing to the environment and humanity. This work agrees that technology is one of the main causes of environmental problems but disagrees that technology is a curse. Technology in itself is value-neutral; it is its usage that leads to bad or good consequences. It is the contention of these researchers, that technology when well driven could restore the health of the environment. Technology due to its wrong positioning in the past has caused environmental problems. It could be repositioned to foster environmental health in the future. Technology therefore, has the potential, to restore and heal what it has wounded, when properly driven.

Keyword: Technology, Curse, Blessing, Environment, Degradation. 


\section{Introduction}

The environment is presently in a bad shape, leading to calls to all humans by environmentalists for a change in attitude towards the environment. It is believed that human activities (industrial, agricultural, transportation, communication, mining, etc) are responsible for the degradation of the environment. These activities are said to be responsible for climatic change, global warming, ozone layer depletion, biodiversity loss, rise in ocean acidity, increase in ocean noise and deforestation [1, 2]. It has been estimated that "about half of the Earth's mature tropical forests - between 7.5 million and 8 million $\mathrm{km} 2$ (2.9 million to 3 million sq $\mathrm{mi})$ of the original 15 million to 16 million $\mathrm{km} 2$ (5.8 million to 6.2 million sq $\mathrm{mi}$ ) that until 1947 covered the planet - have now been destroyed" (Nielsen 2006). Due to this loss of forest which is a habitat of many species, it is believed that many life species are extinct and many more are endangered [1]. In "2006 many species were officially classified as rare, endangered or threatened by scientists; and they also estimated that millions of more species which have not been formally recognized are at risk. About 40 percent of the 40,177 species assessed using the IUCN Red List criteria are now listed as threatened with extinction-a total of 16,119" [3]. The loss in the forest is also believed to be largely responsible for the increasing atmospheric carbon dioxide which is a leading cause of global warming. In May 2013, "it was reported that readings for $\mathrm{CO} 2$ taken at the world's primary benchmark site in Mauna Loa surpassed $400 \mathrm{ppm}$. According to professor Brian Hoskins, this is likely the first time CO2 levels have been this high for about 4.5 million years" [4].

The understanding that human negative activities are the causes of environmental problems has led many environmentalists and scholars to point accusing fingers at technology. This is because technology enhances human's exploitation of the environment. Through the use of technological devices, human beings for instance, are capable of felling down the number of trees in a day that they would have taken years to cut without technology. Technology has brought forth vehicles which are huge sources of carbon emission. Communication technologies make communication easier and faster but have increased the intensity of radiation in the atmosphere. Fertilizers, herbicides and pesticides runoff into streams and rivers, thereby reducing its quality and affecting lives there. Technology and its products daily cause innumerable damage to the ecosystem [5], [6].

Examining the contribution of technology to environmental degradation, many environmentalists see it as a curse to the environment rather than a blessing. Though, many are united in the belief that technology contributes majorly to environmental problems, not all are in agreement that technology should be done away with. Some environmentalists believe that technology in itself is not bad, rather it is the use of it that determines its badness and goodness. They believe that technology if rightly employed could save the environment.

While this work agrees that the argument that leads to the belief that technology is a curse is sound, it believes that the argument that it is neutral is sounder. It feels technology is value-neutral in itself and could be made positive by making it serve the environment.

\section{Technology Impacts Negatively on The Environment}

Development in technology which later led to the Industrial Revolution brought forth improvement in the living standard of human beings. Technology has aided human beings to improve in the food supply, clean water, and comfortable houses and has boosted and bettered the health, transport, communication and other sectors of the human economy. In the United States alone for instance, per capita income after the Industrial Revolution, between 1870 and 1910, rose by 40 percent, and the value of manufacturing output increased sevenfold [7]. Technology could be said therefore to have revolutionized almost all aspects of human life. Despite this good side of technology however, it has left in its wake a polluted environment and depleted resources.

\footnotetext{
Technology impacts on the environment by:

- Increasing Global Warming

- Affecting Water Quality

- Increases Pollution

- Increases Waste

- Increases Power Consumption

- Increases Deforestation

- Increases radiation
} 


\subsection{Increasing Global Warming}

Global warming is the rise in the average temperature of the Earth's atmosphere and oceans [8]. It is reported that since the beginning of the "20th century Earth's mean surface temperature has increased by about $0.8^{\circ} \mathrm{C}\left(1.4^{\circ} \mathrm{F}\right)$ " [9]. Scientists generally believe that "global warming is primarily caused by increasing concentrations of greenhouse gases produced by human activities such as the burning of fossil fuels and deforestation" [10].

The burning of fossil fuel is largely through industrial and technological activities. The effects of global warming include: extreme weather like heat waves, droughts and heavy rainfall; it also include ocean acidification, species extinctions, "rise in sea levels and a change in the amount and pattern of precipitation, as well as a probable expansion of subtropical deserts" [11]. Other effects are a "threat to food security from decreasing crop yields, the loss of habitat from inundation, melting of snow and ice, increase in the heat content of the oceans, increased humidity et cetera" [12]. These changes are deemed to be virtually one hundred percent human-induced [13].

Human activity induced by technology, since the "advent of the Industrial Revolution has continually increased the number of greenhouse gases in the atmosphere; leading to increased radioactive forcing from $\mathrm{CO} 2$, methane, tropospheric ozone, $\mathrm{CFCs}$ and nitrous oxide. In the United States for instance, the energy sector is believed to account for more than 85 percent of total greenhouse gas emissions, with "energy-related carbon dioxide" alone responsible for about 80 percent of these emissions. According to work published in 2007, the concentrations of CO2 and methane have increased by $36 \%$ and $148 \%$ respectively since $1750 \%$.'

In May 2013, "it was reported that readings for CO2 taken at the world's primary benchmark site in Mauna Loa surpassed $400 \mathrm{ppm}$. According to professor Brian Hoskins, this is likely the first time $\mathrm{CO} 2$ levels have been this high for about 4.5 million years" [4]. Among the human activities that have contributed to global warming, Fossil fuel burning alone is said to have "produced about threequarters of the increase in $\mathrm{CO} 2$ from human activities over the past 20 years; and deforestation causing most of the remaining quarters".

\subsection{Affecting Water Quality}

Gaseous emissions (especially nitrogen oxides) from industrial and vehicular emissions are very detrimental to water quality. Nitrogen deposits in water are known to act as fertilizer that promotes the growth of algae in rivers, streams, lakes, estuaries, and oceans. These algae are known to create eutrophic conditions that destroy submerged aquatic vegetation and most times hindering commercial fishing. More damaging to water quality is the agricultural runoff of fertilizer, pesticides and animal wastes. These run off to streams and rivers polluting them and thereby, making them unfit for aquatic lives.

\subsection{Increases Pollution}

Passmore [14] the Australian thinker defines pollution as, "the process of putting matter in the wrong place in quantities that are too large". A place maybe "wrong" aesthetically (as in oil in an estuary; plastic bottles, bags or beer cans in a park); or wrong when it is dangerous to human health; or when it destroys wildlife, plants, or humans.

Technology is believed to have increased the level and rate of pollution of the environment. Due to technological advancement human beings travel more now (most of which are unnecessary) than ever. This increase in travel enhanced by technology contributes directly to air pollution. It could be argued that travels have been a constant activity of human beings but before advancement in technology, its chances of environmental pollution was minimal. Then camels, horses and bulls were relied on for travels, which are time-consuming but nevertheless environmentally friendly, but current technology is so advanced that one can travel from one part of the world to another in a short time. This is great but has a greater risk for human life and the environment. The pollution generated from these travels is huge. It is in the form of air, water and even noise pollution types.

The pollutions pose health hazards. It is estimated that in the United States alone, about 4.5 trillion litres (1.2 trillion gallons) of contaminated water seeping into the ground daily. This comes from septic tanks, cesspools, municipal and industrial landfills and waste disposal sites, agricultural chemicals and wastes [15]. It is also estimated that 1.5 million Americans fall ill from infections caused by fecal contamination which costs billions of dollars per year. Also 6 million metric tons of plastic bottles, packaging materials and other pollutants are thrown into the oceans from ships every 
year, where there choke seabirds, mammals and fishes. Oceanographers estimate about 3 to 6 million metric tons of oil is discharged into the world's ocean each year from oil tankers, fuel leaks, intentional discharges et cetera [15]:

Other examples of water pollutants include:

1. Organic chemicals which include products used in industries, houses and agriculture. Examples are plastics, detergents, oil, gasoline, pesticides et cetera.

2. Inorganic chemicals that emanate from industrial effluents, household cleansing, surface runoff et cetera. Pollutants in this category are acids, caustic, salts, metals et cetera.

3. Radioactive materials emanate from the mining of ores, production of weapons, manufacture of weapons et cetera.

4. Thermal changes like heat which emanates from power plants and industrial cooling.

The major air pollutants include carbon monoxide, ozone, lead, nitrogen oxides, sulphur dioxide, particulate matter. Most of these pollutants are from the burning of fossil fuels, like in coal-powered electric plants, in cars and trucks as well as during the processing of natural gas and oil. According to William Cunningham \& Mary Cunningham [15] about 2 billion metric tons of air pollutants are released into the atmosphere every year worldwide.

\subsection{Increases Waste}

The sources of waste though different in all countries is nevertheless more or less directly or indirectly connected to technology. In Nigeria for instance, the main source of waste comes from drilling activities, which is a technologically driven process.

In the UK, the main source is from mining and quarrying, the construction and demolition of buildings, industry and commerce. One main source of waste in industrial countries is technological up-gradation. A large amount of toxic waste is produced regularly through shifts in technologies. For instance, a shift in computer technology from large-sized computers to laptops has made previous computers become waste, as these are no more needed. Now people prefer to use laptops and tablets due to their compactness and portability, making desktop computers obsolete and thus waste products. Thus, technological upgrading to laptops made large size desktop to be disposed into the environment.

The same is also true of tungsten bulbs which were replaced by florescent bulbs which are now replaced by incandescent bulbs. These out of use items enter the environment as waste products, most of which are non-biodegradable. Waste products pollute the soil, rendering it unfit for plant and animal lives.

\subsection{Increases Power Consumption}

Power consumption is high due to technology. According to Bisong [16] "We are presently spending the potential energy of the biosphere at ten times the rate it is being accumulated by living organisms that can absorb sunlight".

Technology (like phones, television, radios etc) is employed in schools, work environments, at homes and other places. These technologies are powered by electricity, which in itself makes use of fossil or nuclear fuels on a large scale. Fossil fuels and nuclear materials are non-renewable. This means, the high use of technology tantamount to a high depletion of the world energy (fossil and nuclear power), implying that the energy source of the world will soon become inadequate to supply the power need of humans.

\subsection{Increases Deforestation}

The world forest is highly depleted. This is made possible by the development of the higher capacity of machinery technology. Unlike before, today humans through the aid of technology can clear greenery in a very short span and dig through hills and mountains with little stress [17].

An increase in technology makes it possible to build many houses within a short span. Although this appears to be enjoyable for human beings, it has led to the extinction of species. Many scientists believe that today's species extinction rate is highest in history. Deforestation aside from affecting living organism also affects the climate. This is really why there is climatic change present in the world. It is also a reason why the countries still possessing a good percentage of forest area are experiencing a friendly environment. 


\subsection{Increases Radiation}

It is common to see people in houses, parks, offices, and even on roads busy with their mobile phones and tablets. Addicted use of phones and the apps inside, means an increase in WiFi and internet connectivity, which invariably leads to an increase in radiation and consequent health problems associated with this. Scientists believe that some birds get extinct in these WiFi-enabled areas, due to the effects of radiation.

\section{Technology Can Save the Environment}

Many environmentalists see technology as bad in itself and incapable of cleaning up its mess and saving the environment. There are two arguments often raised to support this position. The first argument is based on nature and culture dichotomy. This argument hinges on the widely held belief that culture is opposed to nature. That is, what is cultural is not natural and thus culture is opposed to nature. Since culture is opposed to nature, it implies that technology which is a product of culture is opposed to nature.

The second argument is based on the value of nature. This argument holds that nature is fundamentally valuable in its natural state. But when technology adds to nature, its value is lower than nature in its naturalness. We are asked to imagine some tourists appreciating a given nature set out by technology without knowing that it was not natural. The tourists will enjoy the sites and marveled at the wonders of nature but when they are later told that what they experienced was not really natural, their value for what they experienced drops. This for this group is a pointer that nature created by technology can only be one with a reduced value. Since the value of a technologically induced environment is lower than that of real nature, it means the technology cannot save nature. It can only produce a copy that is lower in value than the real.

While not disagreeing totally with these arguments against technology as a means of environmental restoration, I think the arguments overemphasize the dichotomy between culture and nature. These arguments can only succeed if human beings are separated from nature, which will mean that the products of humans are not natural. But environmentalists would be unwilling to accept this line of argument, for it will be against what they preach. They believe that humans are part of nature and should act in ways that will be harmonious with the environment. If human beings are part of nature, then technology cannot be said not to be natural, for a natural being cannot produce an unnatural thing. This will mean that technology is not unnatural and thus technologically restored or modified environment is not of lower value to naturally existing nature.

We, therefore, stand with those who argue that technology is not negative or positive but neutral. It is the use of technology that makes it either negative or good to the environment. Mostly, the use of technology in the past has tended to affect the environment negatively. Today, most scientists have realized this past negative bend of technology and are making attempts to position technology to contribute positively towards the health of the environment.

The ways technology has been employed or could be employed to save the environment include:

1. Birth control technologies

2. Geoengineering

3. Waste Minimization

4. Bioremediation

5. Stream Restoration

6. Poverty Reduction

\subsection{Birth Control Technologies}

The human population is believed to be one of the basic factors responsible for environmental degradation. Presently, the human population is on the increase, which means the impact of humans on the environment is increasing. This has resulted in calls by environmentalists for the reduction of the human population. Technologists have developed several birth control techniques to achieve this. Birth control aids in the reduction of the size of a family as well as the population of a given country. Birth control fosters economic growth by producing fewer dependent children; allows more women to work, and reduces the consumption of scarce resources which has been the root cause of environmental degradation [18]. 
The methods of birth control include tubal ligation intrauterine devices (IUDs), implantable contraceptives, oral pills, patches, vaginal rings, injections and sterilization by means of vasectomy in males. Others include: barriers such as condoms, contraceptives sponges and diaphragms and spermicides. Sterilization, though highly effective, is not reversible; other methods could be reversed. By developing technologies for population control, it shows that technologists are heeding the calls of environmentalists to control the rate of growth of the human population for environmental reasons. Ikwun [19] in recognition of the importance of birth control technologies asserts: "overpopulation puts the scarce resources under pressure and degrades the environment and abortion could help to stem this".

\subsection{Geoengineering}

Geoengineering or climate engineering is another attempt by technologists to resolve environmental problems. It refers to the large-scale interference in the "Earth's climatic system" to reduce global warming (Royal Society Geoengineering the Climate: Science, Governance and Uncertainty 1). The term encompasses two categories of technologies which are - solar radiation management and carbon dioxide removal. Carbon dioxide removal geoengineering attempts to remove carbon dioxide from the atmosphere and thereby reducing the greenhouse gases in the atmosphere while "solar radiation management" attempts to neutralize the harmful effects of greenhouse gases by helping the Earth to absorb less solar radiation. Solar radiation management could be achieved by "deflecting sunlight away from the Earth, or by improving the reflectivity of the Earth's surface".

Solar radiation management techniques include:

1. Increasing the reflectivity of clouds by using, for example, fine sea water spray to whiten the clouds.

2. Using pale-coloured roofing and paving materials to improve the reflectivity of the earth.

3. Creating reflective aerosols, such as "stratospheric sulfur aerosols, aluminium oxide particles, even specifically designed self-levitating aerosols" ("Photophoretic levitation of engineered aerosols for geoengineering". PNAS).

4. Creating Space sunshade that would aid in the obstruction of "solar radiation with space-based mirrors, asteroid dust" [20].

5. Reforestation to cause a "positive biophysical change such as the formation of clouds". These clouds assist in reflecting sunlight and thereby creating a positive impact on climate mitigation [21].

Carbon dioxide removal technology, on the other hand, aims at removing greenhouse gases from the atmosphere through the following techniques:

1. Creating "biochar" and mixing it with soil to create "terra preta".

2. Creating "Bio-energy" with carbon capture and storage to requisition carbon and concurrently provide energy for man's use.

3. "Carbon air capture" to remove carbon dioxide from the air.

4. Planting trees to counterbalance carbon emissions.

5. "Ocean nourishment" which includes iron fertilisation of the oceans.

\subsection{Waste Minimization}

Waste Minimization is the process of reducing the amount or quantity of waste produced by a person or a society. It involves conscious efforts to reduce resources and energy used during the production process. For the same output, the fewer materials used, the less waste is produced. Waste minimization from industrial production could follow a variety of processes, which include:

1. Reuse of scrap material - to minimize waste, many industries re-incorporate scraps at the beginning of production so as there will not become a waste product.

2. Resource optimisation involves the conscious minimisation of the amount of waste produced by individuals or organisations by optimising the use of raw materials. For example, a tailor could cut a piece of fabric in such a way that no part of it is wasted. 
3. Fitting the intended use. This is the conscious effort to design products to fit the intended use. Products not fitting the intended use would tend to become waste products.

4. Improving Durability. Improving product durability, such as extending a radio useful life to 15 years instead of 12 , can reduce waste and improves resource optimisation.

\subsection{Bioremediation}

Bioremediation is a technology that involves the "use of micro-organism metabolism to remove pollutants". It is a "process through which metal contaminants are modified as a direct result of microbial activity" (NRC 72). The objective may be to immobilize, mobilize, or decrease the toxicity of metals in the soil or water depending on the goals of the remediation.

Bioremediation could be through the introduction of new micro-organisms to a contaminated site, or the adjustment of the conditions of the environment to improve the degradation rates of indigenous fauna. "Bioremediation can be applied to recover brownfields for development and for preparing contaminated industrial effluents prior to discharge into waterways.

Bioremediation technologies are also applied to contaminated wastewater, ground or surface waters, soils, sediments and air where there has been either accidental or intentional release of pollutants or chemicals that pose a risk to human, animal or ecosystem health" (http://biotech.about.com/od/glossary/g/bioremed.htm). Naturally existing microorganisms have been used in the past to break down industrial, agricultural and municipal organic wastes. Today, however genetically engineered organisms are being employed to clean-up industrial effluent, polluted soil and also petroleum spills [22]. The "bacterium Deinococcus radiodurans (the most radio resistant organism known) has been modified to consume and digest toluene and ionic mercury from highly radioactive nuclear waste" [23]. Bioremediation presently treats about 5-10 percent of all toxic chemicals and waste. It treats oil, gasoline, toluene, naphthalene, pentachlorophenol, and agricultural waste

\subsection{Stream Restoration}

Technologies are also applied to restore the health of streams. Stream or river restoration is a set of activities that are geared towards the improvement of the health of a river or stream. Improved health could be effected through the expansion of the habitat of diverse species and the reduction of stream bank erosion. Improved health may also include "improved water quality (i.e. reduction of pollutant levels and increased dissolved oxygen levels) and achieving a self-sustaining, functional flow regime in the stream system that does not require periodic human intervention, such as dredging or construction of flood control structures" [24].

Restoration activities could include: "removal of a disturbance which inhibits natural stream flow, stabilization of stream or river banks, installation of stormwater management facilities, such as riparian zone restoration and constructed wetlands" [25]. Most pollutants of streams and rivers come from runoff of pesticides and fertilizers applied to farms. However, in the past few years, the technologies of geographic information systems (GIS) using remotely sensed data have been developed to aid the identification, observation and control of these sources of pollution. While it may be impossible to trace all the runoff to its source, it is increasingly possible through the use of modern technologies to trace much of it. GIS tools have also enhanced and encouraged precision farm practices using computerized real-time and detailed information about crop health. Remote sensors are also helping farmers to know which row of crops are suitable for irrigation and also for fertilizer and pesticide applications. This is to ensure that crops yields are better and the use of chemicals is reduced (Austin 2018).

\subsection{Poverty Reduction}

Poverty Reduction has been widely accepted that poverty is one source of environmental degradation. Such acceptance has been made by the "Brundtland Commission report Our Common Future and the Millennium Development Goals" (United Nations Environment Programme 2008). According to the "Brundtland" report, "poverty is a major cause and effect of global environmental problems. It is therefore futile to attempt to deal with environmental problems without a broader perspective that encompasses the factors underlying world poverty and international inequality". Individuals "living in poverty tend to rely heavily on their local ecosystem as a source of basic needs (such as nutrition and 
medicine) and general well-being [26]. For example, the poor tend to depend heavily on the charcoal to cook, which increases deforestation, teaching them to use recyclable materials, such as recycled plastics for lumber would produce no useful result because of poverty. Technology, by creating jobs for people have already elevated many from the poverty line. This means that technology by reducing poverty in the world is indirectly contributing to the resolution of environmental problems.

\section{Conclusion}

Technology may not be able to solve all environmental problems, but it has great potentials (when rightly targeted) of reducing them and restoring environmental health. The internet for instance when well-targeted, holds great promise, for it could offer rich data archives and retrieval systems for researchers on the environment. It could also help in speedy exchange of data, research results and scientific modelling of complex environmental processes between/among distant researchers and software for scientific modeling of complex environmental processes. The Internet could also greatly help in the spread of environmental information to the general public. It could create much awareness of environmental problems and their causes.

Other technologies that could save the environment are green cars and biofuels (which is renewable). The term "green cars" encompasses both electric cars and cars that use fossil fuel but consume less of it. Actualizing this dream (of using green cars and switching from fossil fuel to biofuel) offers great hope to the environment since transportation and burning of fossil fuel are major causes of environmental problems. Other technologies that hold great potentials for saving the environment include: biofiltration, bioreactor, desalination, doubly-fed electric machine, energy conservation, energy-saving modules, electric vehicles, wave energy, green computing, hydroelectricity, wind power, wind turbine, hydrogen fuel cell, ocean thermal energy conversion, Solar power, photovoltaic, thermal depolymerization, Composting toilet and pyrolysis

These technologies are critical to saving the environment from imminent collapse, by reducing global warming, climatic change, ocean acidity, pollution, etc and in addition to this, human health will be fostered.

\section{References}

[1] B. P. Bisong, "The Constraining Mechanisms and Sustainable Environment," OmniScience: A Multi-disciplinary Journal, vol. 9, no. 1, pp. 47-55, 2018.

[2] P. J. Mendie, and E. Eyo, "Environmental Challenges and Axiology: Towards A Complementary Studies in Eco-Philosophy," Journal of Integrative Humanism, vol. 7, no. 1, pp. 144-150, 2016.

[3] R. Lovett, "Endangered Species List Expands to 16,000," national geographic news, 2018. [Online]. Available: http://news.nationalgeographic.com/news/2006/05/0502_060502_ endangered.html. [Accessed: May. 15, 2019].

[4] BBC, Carbon Dioxide Passes Symbolic Mark. 2018. [Online]. Available: http://www.bbc.co. uk/news/science-environment-22486153. [Accessed: May. 10, 2019].

[5] J. N. Ogar, "Ethical Implication of Environmental Crises on African Societies: A Challenge to Future Humanity," International Journal of Environmental Pollution and Environmental Modelling, pp. 109-115, 2019.

[6] S. A. Bassey, “Anthropoholism' As an Authentic Tool for Environmental Management," International Journal of Environmental Pollution and Environmental Modelling, pp. 160-168, 2019.

[7] S. A. Bassey and Jr. T. M. Pimaro, "Enyimba's Notion of Madukaku and the Question of Anthropocentricism in African Environmental Ethics," International Journal of Environmental Pollution and Environmental Modelling, pp. 129-136, 2019.

[8] B. P. Bisong, and A. S. Sunday, "The Noetic Propaedeutic Pedagogy as a Panacea to Environmental Degradation," Canadian Social Science, vol. 10, no. 4, pp. 37-46, 2014.

[9] America's Climate Choices: Panel on Advancing the Science of Climate Change; National Research Council (2010). Advancing the Science of Climate Change. Washington, D.C. The National Academies Press, 2010. 
[10] IPCC, Synthesis Report, Section 1.1: Observations of climate change. 2013. [Online]. Available: http://www.ipcc.ch/ publications-and-data/ar4/syr/en/mains1.htm. [Accessed: July. 10, 2013].

[11] J. Lu, V. Gabriel, and R. Thomas, "Expansion of the Hadley cell under global warming," Geophysical Research Letters, vol. 34, no. 6, 2007. [Online]. Available: http://www.atmos.berkeley.edu/-jchang/class/spr07/Geog257/week10/lu-hadley06.pdf. [Accessed: May. 10, 2018].

[12] D. Battista, "Historical warnings of future food insecurity with unprecedented seasonal heat," Science, vol. 323, no. 5911, pp. 240-424, 2009.

[13] J. Kennedy, "How do we know the world has warmed? State of the Climate in 2009," Bull.Amer.Meteor.Soc, vol. 91, no. 7, pp. 26, 2010.

[14] J. Passmore, Man's Responsibility for Nature. Ecological Problems and Western Traditions. London: Gerald Duckworth and Co, 1974.

[15] W. Cunningham, and C. Mary, Principles of Environmental Science: Inquiry and Application. $3^{\text {rd }}$ edition. New York: McGraw-Hill, 2006.

[16] P. B. Bisong, An Ethic of Sustainable Environment from Ibuanyidanda's Perspective. Germany: Lambert Academic Publication, 2016.

[17] E. O. Duke, "From Christian spirituality to eco-friendliness," International Journal of Humanities and Innovation (IJHI), vol. 3, no. 1, pp. 34-38, 2020.

[18] D. Canning, and S. Paul, The economic consequences of reproductive health and family planning. The Lancet, vol. 380, no. 9837, pp. 165-171, 2012.

[19] R. Ikwun, and G. Ntamu, "Over Population and the crises of Hunger and Property in SubSaharan Africa: The Way Out," An African Journal of Philosophy, vol. 9, no. 1, pp. 108-115, 2006.

[20] R. Berwick, "Julian Sanchez; C. R. McInnes. Gravitationally bound geoengineering dust shade at the inner Lagrange point," Advances in Space Research, vol. 50, no. 10, pp. 1405, 2012.

[21] J. Canadell and R. Micael "Managing Forests for Climate Change," Science (AAAS) vol. 320, no. 5882, pp. 1456-1457, 2008.

[22] D. Lovley, "Cleaning up with Genomics: applying Molecular Biology to Bioremediation," Nature Reviews. Microbiology, vol. 1, no. 1, pp. 35-44, 2003.

[23] H. Brim, "Engineering Deinococcus radiodurans for metal remediation in radioactive mixed waste environments," Nature Biotechnology, vol. 18, no. 1, pp. 85-90, 2000.

[24] J. Gilman, and K. Jarrod, "Challenges of Stream Restoration as a Stormwater Management Tool; Part 1: A designer's perspective," Stormwater, vol. 10, no. 3, pp. 36, 2009.

[25] A. Cronin, "Restoring Paradise in Moscow, Idaho," Land and Water. vol. 47, no. 2, pp. 18, 2003.

[26] O. Kobtzeff, "Environmental Security and Civil Society," Central and South-central Europe in Transition. Westport. Ed. H. Gardner. Connecticut: Praeger, 2000. 